\title{
A COMPARATIVE STUDY OF THE PRIMARY VASCULAR SYSTEM OF CONIFERS. I. GENERA WITH HELICAL PHYLLOTAXIS ${ }^{1}$
}

\author{
Kadambari K. Namboodiri² and Charles B. Beck \\ Department of Botany, University of Michigan, Ann Arbor
}

A B $\mathbf{S}$ T $\mathbf{R}$ A $\mathbf{C}$ T

\begin{abstract}
The primary vascular system of 23 species belonging to 18 genera of conifers with helical phyllotaxis has been investigated with the intent of determining the architecture of the system. Special attention has been given to nodal and subnodal relations of the vascular bundles. The vascular system seems to be composed solely of relatively discrete sympodia, that is, axial vascular bundles from which leaf traces branch unilaterally. Although the discreteness of the sympodia is not immediately apparent because of their undulation and lateral contacts with neighboring ones, close examination, including a statistical analysis of the tangential contacts, seems to reveal that each sympodium maintains its identity throughout. Although two traces may be apparent at nodal levels, the trace supply to a leaf originates, in all species, as a single bundle. An analysis is made of the relationship between the vasculature and the phyllotaxis. It is observed that the direction of trace divergence can be accurately predicted when the direction of the ontogenetic spiral, the angle of divergence of leaf traces, and the number of sympodia are known.
\end{abstract}

THE ORIGIN and evolution of gymnosperms are significant problems that deserve increased attention. There have been few modern comparative studies of extant gymnosperms, and most of the important contributions to the solution of these problems have come from investigations of fossil forms. The present study, in three parts, of the primary vascular system of a large number of living conifers as well as a consideration of the stelar structure of fossil gymnosperms was undertaken in an effort to add further to our understanding of the origin and evolution of gymnosperms.

Any comparative study of the primary vascular system must, of necessity, include a consideration of stelar evolution, which will be the subject of the third part of this study. Parts I and II deal with the structure of the primary vascular system of some living conifers.

It is clear that the primary xylem is a useful tissue system in the study of phylogenetic relationships of vascular plants. Jeffrey (1899) included the Filicineae, Gymnospermae and Angiospermae in the Pteropsida in large part on the basis of the possession in all of what he believed to be similar stelar structure. He regarded the primary vascular systems of gymnosperms and angiosperms to have evolved from

\footnotetext{
${ }^{1}$ Received for publication 17 July 1967.
}

This paper is based on part of a Ph.D. thesis by the first author.

The authors express their appreciation to Dr. N. K. Namboodiri, Department of Sociology, University of North Carolina, for his great assistance in making the statistical analysis reported herein.

${ }^{2}$ Formerly known as G. Kadambari Kumari. Present address: Genetics Program, University of North Carolina, Chapel Hill, N.C. 27514. that of the ferns by reduction (Jeffrey, 1902, 1917). Consequently, he considered the leaf gap of seed plants to be homologous with that of the ferns. This view is still widely accepted today, especially among comparative morphologists and systematists.

Whereas the morphology of the primary vascular system of ferns has been intensively studied and, in general, has been well understood for many years, the primary vascular system of seed plants is less well understood in terms of its three-dimensional morphology. This is especially true of gymnosperms.

The first major comparative study of the primary vascular system of seed plants in this century was that of Sinnott (1914) in which nodal anatomy was emphasized. Sinnott concluded that the primitive and basic nodal type in dicotyledons is the trilacunar condition. He regarded the unilacunar condition as derived from the basic type by reduction and elimination of the lateral traces and gaps, and the multilacunar condition by the amplification of the number of independently attached lateral strands with their corresponding lacunae. Eames (1931) concluded that the three-veined carpel is primitive, thus supporting the conclusions of Sinnott.

A reinterpretation of the evolution of nodal types seemed to be necessary, however, when it was extended to the entire Pteropsida. Taking into account a wider array of evidence, Marsden and Bailey (1955) proposed a fourth type, the unilacunar two-trace node, as the primitive and basic type in Pteropsida. This type of nodal structure, however, is very uncommon in gymnosperms, and especially so in the conifers. 
One of the early studies of the primary vascular system of gymnosperms was that of Geyler (1867). In most conifers and Ginkgo he found one or two traces extending from the leaf in a basipetal direction and becoming united with another vascular strand in the stem supplying an older leaf in a unilateral sympodial fashion. The work of deBary (1884), Bertrand (1874), and Barthelmess (1935) confirmed, in general, the views of Geyler. Hill and De Fraine (1913) who worked on conifer seedlings also noted that the cotyledons are supplied with single traces in most cases. More recently, Crafts (1943) and Sterling (1945) investigated intensively the primary structure of Sequoia sempervirens. Sterling later (1947) studied Pseudotsuga taxifolia. These studies corroborated the occurrence of the sympodial vascular pattern and single trace condition described by previous workers.

On the basis of some of the earlier of these observations, Florin (1931) interpreted the primary vasculature of coniferophytes in terms of the telome hypothesis. Gunckel and Wetmore (1946), however, concluded from their study of the vasculature of the short and long shoots of Ginkgo biloba that the two bundles supplying a leaf are not the products of a single dichotomy of one bundle. They clearly established that the two bundles arise as branches from two independent bundles. This seemed to negate the telomic interpretation of foliar trace dichotomy in Ginkgo and suggested the possibility of a misinterpretation of the primary vascular system by some earlier-workers who described the two leaf traces of some conifers as originating as a single bundle.

The condition found in Ginkgo is very similar to the nedal structure found in Ephedra (Marsden and Steeves, 1955), in some primitive Ranalean plants (see Benzing, 1967a, b), and in Clerodendron trichotomum (Marsden and Bailey, 1955). The occurrence of this condition in Ginkgo seemed to be a strong argument for considering it to be the basic, primitive condition in Pteropsida. We do not, however, have any reliable assurance that this generalization can be applied validly to the Coniferales and other gymnosperms. The fact is that we do not know the exact situation in most conifers. In many conifers two traces have been reported at the nodal level, but whether they are related to the same bundle or to two different bundles as in Ginkgo has to be ascertained. In cases where the trace is single at the nodal level, we are not certain whether or not this is the primitive condition or one derived by the approximation and fusion of an original pair of traces, or one derived by extreme reduction of one member of an original pair related to the xeromorphic adaptations of the leaf, as suggested by Bailey (1956).

The solution of these problems through an analysis of the stelar architecture of a large number of conifers is the major objective of parts I and II of this study.

Materials AND METHods-Shoot apices were collected from mature plants during April-June, 1961 and 1962, from the Nichols Arboretum, the Botanical Gardens, and the Central Campus of the University of Michigan, Ann Arbor. Voucher specimens of mature plants from which shoot apices were collected are on file in the University of Michigan Herbarium. Seedlings were grown from seeds obtained from Herbst Brothers, Seedmen, Inc., 678 Broadway, New York, N. Y. 10012; Schumacher, Horticulturist, Sandwich, Mass.; and the Botanical Gardens, University of Michigan. The shoot apices of the conifer seedlings were collected when the plumule had grown to a distance of about an inch above the cotyledons. The time interval to attain that height varied widely among the seedlings.

Apices were killed, fixed and stored in formalinaceto-alcohol (FAA).

For processing the materials, embedding and staining methods outlined by Johansen (1940) were followed. Both transverse and longitudinal sections were made $10 \mu$ thick. Embedded materials which were difficult to section were soaked in distilled water for 12-24 hr, after which better results were obtained. The sections were stained with $1 \%$ safranin for $24 \mathrm{hr}$, counterstained with $0.5 \%$ fast-green for $1 / 2-1 \mathrm{~min}$, and were mounted in piccolyte.

Whole mounts of cleared shoot apices of seedlings were also prepared following the procedures of Sporne (1948) and Bisalputra (1960), to supplement the paraffin sections. These were used only in studying the gross pattern of the primary vascular system in relation to the leaf arrangement.

The major technical goal of the investigation was to gain accurate information regarding the course of the vascular bundles of the different species. In order easily to comprehend the nature of the entire vascular system of the shoot apex, diagrams were prepared of the vascular system as if it were vertically split open and spread on a flat surface with the outer surface facing the observer (see Fig. 1). For details of the method by which such a picture is obtained, refer to Kumari (1963).

Such diagrams show: (1) the upward course of the vascular bundles from an arbitrarily chosen point, (2) the point of division of the bundles, (3) their lateral contacts, and (4) the point of origin of leaf traces. These reconstructions of the vascular system are drawn to scale in the vertical plane, but lateral distances between the bundles are exaggerated. The comparative analysis of the pattern of the primary vascular system attempted in this study is mainly based on such diagrams prepared for each species. These analyses have been supplemented by 
observations of the vascular bundles in longitudinal sections and cleared whole mounts.

Terminology-The organization of the primary vascular system in higher plants is intimately related to the leaf arrangement or phyllotaxis. Hence, the description of the primary vascular pattern is greatly aided by the employment of several phyllotactic terms (Kumari, 1963). Phyllotactic and other terms of especial significance to an understanding of this study are defined below.

1. Sympodium is a fairly discrete, axial vascular bundle from which leaf traces diverge at regular intervals (Barthelmess, 1935).

2. Sympodial segment is a new term introduced in the present study to refer to the segment of a sympodium between the points of origin of any two successive leaf traces along the sympodium. The segment is referred to by the number of the immediately succeeding leaf trace in that sympodium. Thus the sympodial segment between the points of origin of two successive leaf traces along one sympodium, say, $n$ and $n-5$ will be referred to as $n-5$.

3. Leaf trace is defined as the vascular bundle extending from its junction with another strand in the stem to the base of the leaf. (This definition is a slightly modified version of the one given by Esau, 1960.)

4. Dextrorse trace divergence denotes the divergence of the leaf trace from the right side of the sympodium as observed from the outside.

5. Sinistrorse trace divergence denotes the divergence of the leaf trace from the left side of the sympodium as observed from the outside.

The term trace linkage has been used by Sterling (1945) to denote the origin of new sympodial segments. In view of the evolutionary modifications in the primary vascular system to be proposed in a later paper, it has seemed preferable, in the present work, to emphasize leaf trace origin instead. Therefore, the new term, trace divergence has been employed.

6. Leaf gap-There are two prevalent but not necessarily mutually exclusive concepts of the leaf gap. The older and still widespread concept is that of many comparative morphologists and systematists who think of the leaf gap of seed plants and ferns, i.e., pteropsids, as a discontinuity of primary vascular tissue in a siphonostele above the point of divergence of a leaf trace. Following Jeffrey, they consider the seed plant eustele to be a modified, reduced siphonostele, and thus consider the region in seed plants referred to as a leaf gap to be homologous with the leaf gap of siphonostelic ferns. The confluence of the gap with interfascicular parenchyma and the impossibility of longitudinal delimitation in many eusteles is considered to be simply the consequence of great reduction of primary vascular tissue through time.

On the other hand, many botanists use the term leaf gap in a primarily descriptive sense, as a region of interfascicular parenchyma opposite a diverging leaf trace (see Esau, 1965). Used in this way, for example, in the designation of a region in transverse section, or for comparing types of nodal anatomy, there may be no inference regarding the three-dimensional form of the "structure" or of its homology with that of any other group.

In this series of papers the term leaf gap, when used in reference to seed plants, will have this latter sense.

Description-The primary vascular system of 23 species representing 18 genera of conifers has been analyzed. The resulting data are included in Table 1. The vasculature of one species, Abies concolor, will be described in detail in order to illustrate a typical sympodial pattern as well as to provide a better concept of the approach and the type of evidence used in making some of the conclusions.

Vasculature in Abies concolor-A terminal segment of a shoot apex $5.7 \mathrm{~mm}$ long bearing 33 leaves arranged in a sinistrorse ontogenetic spiral was examined by serial transverse sections, selected representatives of which are shown in Fig. 1-17. The average angle of divergence between successive leaves is found to be $138^{\circ} 30^{\prime}$ which is close to the limiting angle of divergence, $137^{\circ} 30^{\prime} 6^{\prime \prime}$, characteristic of the Fibonacci series (see Sterling, 1945; Chandler, 1950). From a study of the transverse sections, a composite diagram of the primary vasculature of Abies (Fig. 1) was prepared. It represents the view of the vascular cylinder as if it were split open and laid out on a flat surface with the outer surface facing the observer. There are 13 sympodia, and the direction of the ontogenetic spiral is from right to left in the sinistrorse direction. The divergence of successive leaf traces along each sympodium occurs at intervals of 13 nodes and is also sinistrorse. Another important feature which has been found to be characteristic of all plants with 13 sympodia is the occurrence of four intervening sympodia between any two sympodia from which traces to successive leaves diverge along the ontogenetic spiral. For example (in Fig. 1), sympodia VIII, IX, X, and XI intervene between sympodium VII, from which trace 29 diverges, and sympodium XII from which trace 30 diverges. The vertical relation of the leaf traces and the sympodial segments may be seen by tracing the upward course of any one sympodium. For example, sympodium XII branches, giving rise to trace 30 and sympodial segment 17. Branching of sympodial segment 17 , at a higher level, results in trace 17 and 


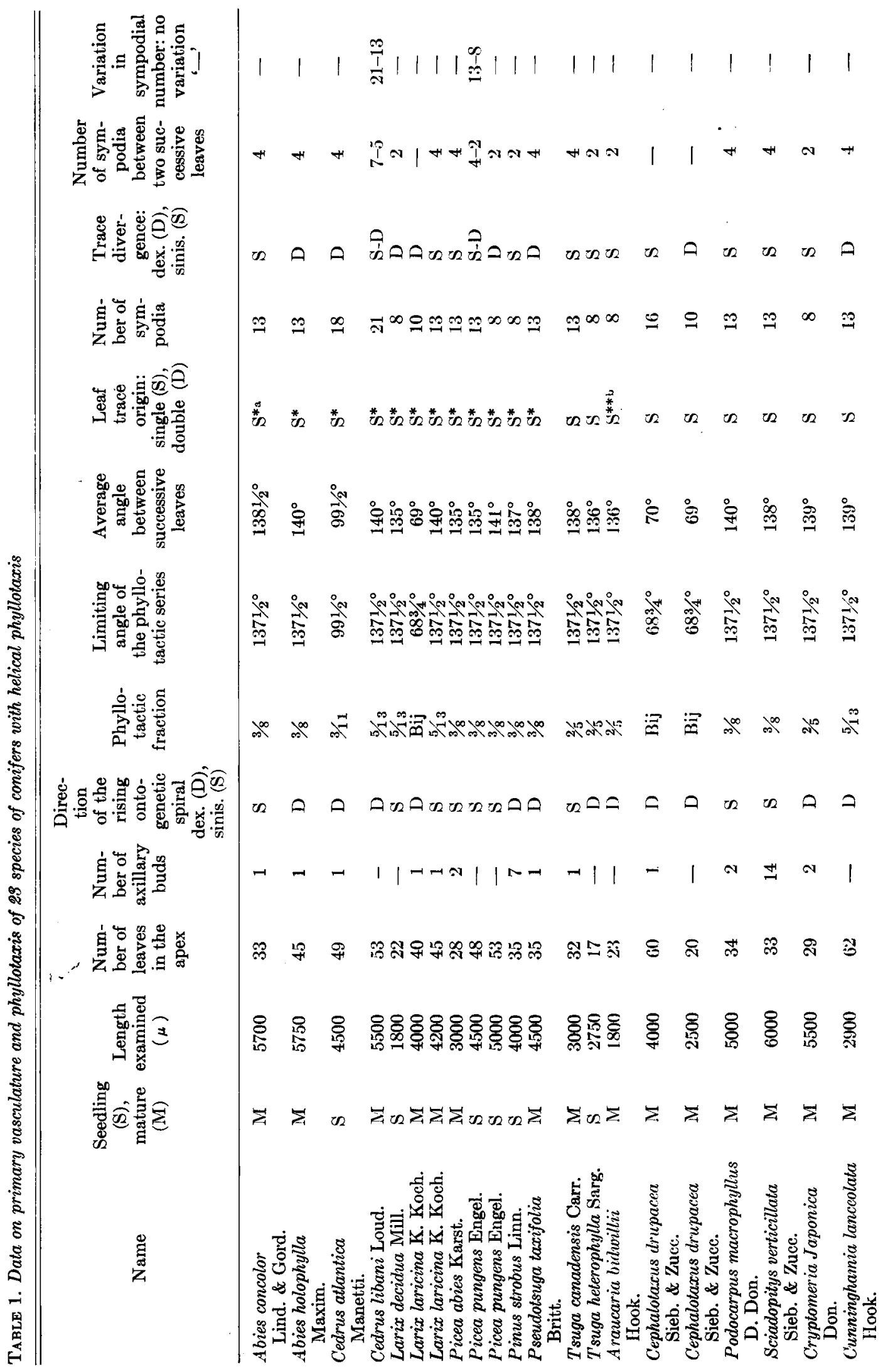




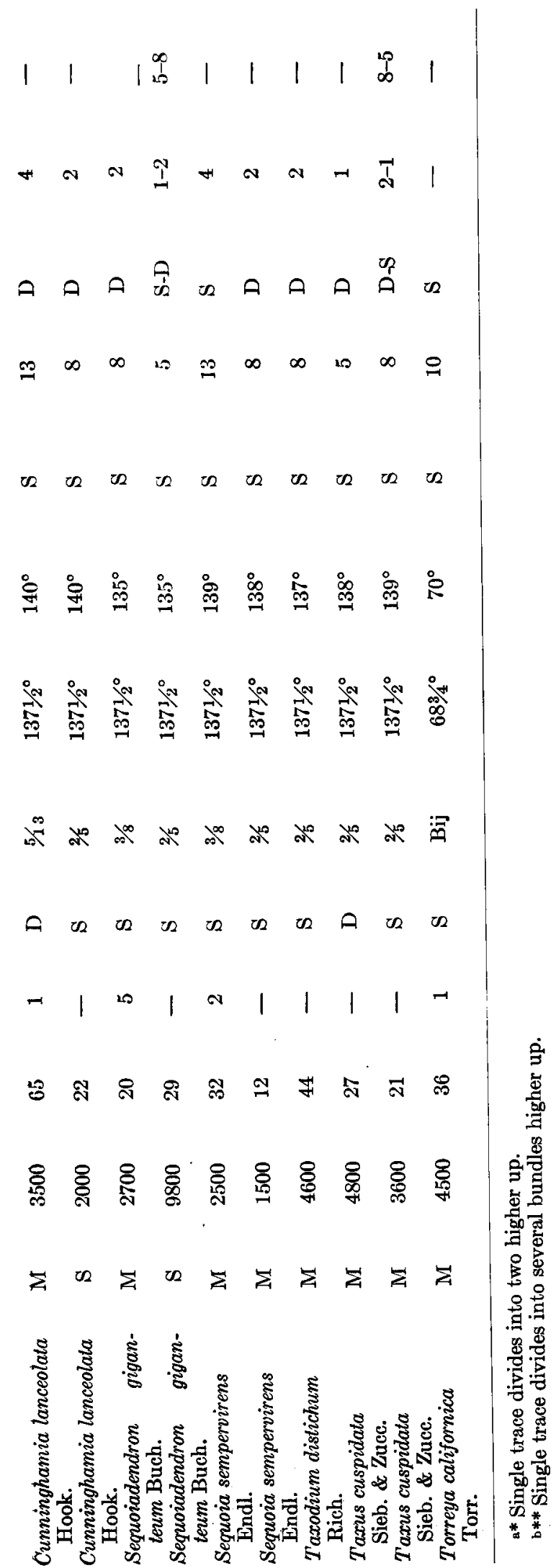

sympodial segment 4 (at an interval of 13 nodes). The same pattern may be seen for all the sympodia.

Regarding the tangential contacts, it can be seen in Fig. 1 that sympodial segment 17 of sympodium XII diverges obliquely to the right from the point of its origin and comes in contact with sympodial segment 25 . Separating from sympodial segment 25 , it has a different course and at a higher level comes in contact with segment 9. These tangential undulations of the sympodia and contacts between sympodial segments are documented by Fig. 2-17. Figure 2 shows the origin of sympodial segment 17 . Figures 3-7 show the contact of segment 17 with segment 25 on the right, from which it separates and diverges (Fig. 8). The contact established between segment 17 and segment 9 can be seen in Fig. 8-16. Figure 15 shows the division of segment 17 into trace 17 and segment 4 , and Fig. 17 shows the divergence of trace 17 from segment 9 . Similar upward courses and trangential contacts and divisions of bundles at 13-node intervals characterize the other 12 sympodia in Fig. 2-17.

Similar sympodial patterns with minor deviations in the number of sympodia and angle of divergence characterize all the conifers with alternate and bijugate phyllotaxis investigated in the present study. Data collected from all the species studied are summarized in Table 1.

Discussion AND INTERPRETATION-An attempt is made here to interpret the data from the present investigation and to correlate them with the findings of earlier workers.

Occurrence of the sympodial pattern-The vascular systems of the shoot apices of the mature and seedling plants of all the conifers investigated show a sympodial pattern. Each bundle in the stem during its upward undulating course divides at regular intervals, giving rise to a leaf trace and a sympodial segment. This work, therefore, supports the description of the sympodial pattern of the vascular architecture in some conifers by Geyler (1867), Barthelmess (1935), Crafts (1943), Sterling (1945, 1947), and Camefort (1956) and extends it to include 15 additional species of conifers.

Discreteness of the sympodia-As has been demonstrated, the bundles during their upward course make tangential contacts with neighboring bundles. These vary from mere lateral placement and close approximation to apparent fusion between bundles. Nevertheless, observational evidence from this and previous studies suggests that the vascular system in conifers is composed of a number of essentially separate sympodia. Additional support for this interpretation of a quantitative nature would, however, considerably 
increase its validity in making phylogenetic conclusions. Assuming that each sympodium is discrete, irrespective of the nature of the tangential contact, it is possible to deduce the following statistical hypothesis.

In Fig. 18 let $\mathrm{AF}$ be the sympodial segment that divides into leaf trace FD and new sympodial segment $\mathrm{FC}$ at the point $\mathrm{F}$. Let $\mathrm{BE}$ be the bundle that makes tangential contact with AF. When AF divides into FD and FC, the number of cells in AF is partitioned into two sets, one forming FD and the other forming FC. Hence the number of cells in FC near $F$ must be less than the number of cells in AF near $\mathrm{F}$. Further, if $\mathrm{AF}$ alone is responsible for the formation of $\mathrm{FD}$ and FC, the difference between the number of cells in $\mathrm{AF}$ and $\mathrm{FC}$ near $\mathrm{F}$ must be highly correlated with the number of cells in FD near $F$. And if the tangential contact of $\mathrm{BE}$ has little or nothing to do with the formation of FD, the difference in the number of cells between two points on BE just before contact and just after separation must not show any correlation with the number of cells in FD.

In order to test this hypothesis, the most accurate method would be to count all the cells at the five levels ( $a, b, c, d$, and e) shown in Fig. 18 in finding the correlation between $\left(a^{\prime}-c^{\prime}\right)$ and $d^{\prime}$ and that between $\left(b^{\prime}-e^{\prime}\right)$ and $d^{\prime}$, where $a^{\prime}$, $b^{\prime}, c^{\prime}, d^{\prime}, e^{\prime}$ denote the number of cells at the levels a, b, c, d, e, respectively. However, due to practical difficulties in counting all the cells in the bundles, only the xylem cells at these five levels have been counted. Such data have been collected for 14 species at $10-16$ nodes. (The data are reported in detail in Kumari, 1963.) In making the counts secondary wall deposition has been taken as the criterion for the xylem cells, and even cells with protoplasts were counted if they showed secondary wall thickening. The coefficients of correlation are shown in Table 2.

As can be seen from Table 2, there is a positive correlation between the number of xylem cells at $d$ and the difference in the number of cells at a and c (Fig. 18). This is significant at the $1 \%$ level in 10 of the 14 species examined and at the $5 \%$ level in the remaining 4 species. In all these species the correlation between the number of cells at $\mathrm{d}$ and the difference between the number of cells at $b$ and e has been found to be significant.

Even though these results are subject to the limitations imposed by the small size of the sample and by the fact that only the xylem cells have been taken into account, they seem to suggest strongly that the identity of the sympodia is retained through regions of lateral contact with adjacent sympodia.

Because the vascular bundles are apparently discrete, and leaf traces are simply branches from continuing bundles, one is prompted to question the view that the leaf gaps of conifers are homologous with those of siphonostelic ferns. One may at least suggest that there is no evidence from this study of a large number of conifers to support such an hypothesis.

Leaf traces-In all of the specimens studied the leaf traces are found to originate singly whether or not they divide later in the cortex or in the leaf. Thus the situation in conifers of helical phyllotaxis does not parallel that described in Ginkgo by Gunckel and Wetmore (1946) in which the two traces at the nodal levels are associated with two bundles at subnodal levels. Hence, Bailey's (1956) suggestion that the single-trace condition in conifers may be the result of fusion of two traces at lower levels does not seem to hold good in conifers with helical phyllotaxis.

Relationship of vasculature and phyllotaxisConsidering the intimate relationship between phyllotaxis and the vascular system, Sterling (1945) suggested that the bundle arrangements can be best described by taking into account (1) the direction of the ontogenetic spiral, (2) the angle of divergence, (3) the sympodial number, and (4) the direction of trace linkage (trace divergence, as used in this study). It may be noted that while trace divergence is useful in determining the sympodial number, it is redundant when the other three characteri tics are known. Hence, any sympodial pattern can be fully described in terms of the first three characteristics enumerated above. These characteristics of the specimens examined in this study are discussed below.

Fig. 1-8.-Fig. 1. Primary vascular structure of Abies concolor. A composite diagram of the outer perspective of the split-open vascular cylinder showing 13 vertical sympodia numbered at the bottom. The leaf traces.(shown terminating in triangles) are numbered in their ontogenetic sequence, increasing values denoting increasing age, and negative values referring to traces to unformed future leaves. The directions of the ontogenetic spiral and trace divergence are sinistrorse. Along each sympodium traces originate at intervals of 13 nodes, and traces of the same sympodium diverge outward through the same longitudinally continuous interfascicular parenchyma. During the upward course each sympodial segment first undulates to the right and then to the left. There are four intervening sympodia between any two from which traces to successive leaves diverge along the ontogenetic spiral.-Fig. 2-8. Primary vascular structure of $A b i e s$ concolor. Series of transverse sections from successive levels of an apex showing the details of an upward course of the vascular bundles. The sections are indicated by their distances below the summit of the apical dome. The traces and the sympodial segments are designated by their ontogenetic sequential number as in Fig. 1. The features summarized in Fig. 1 can be traced in these diagrams, $\times 70$. 

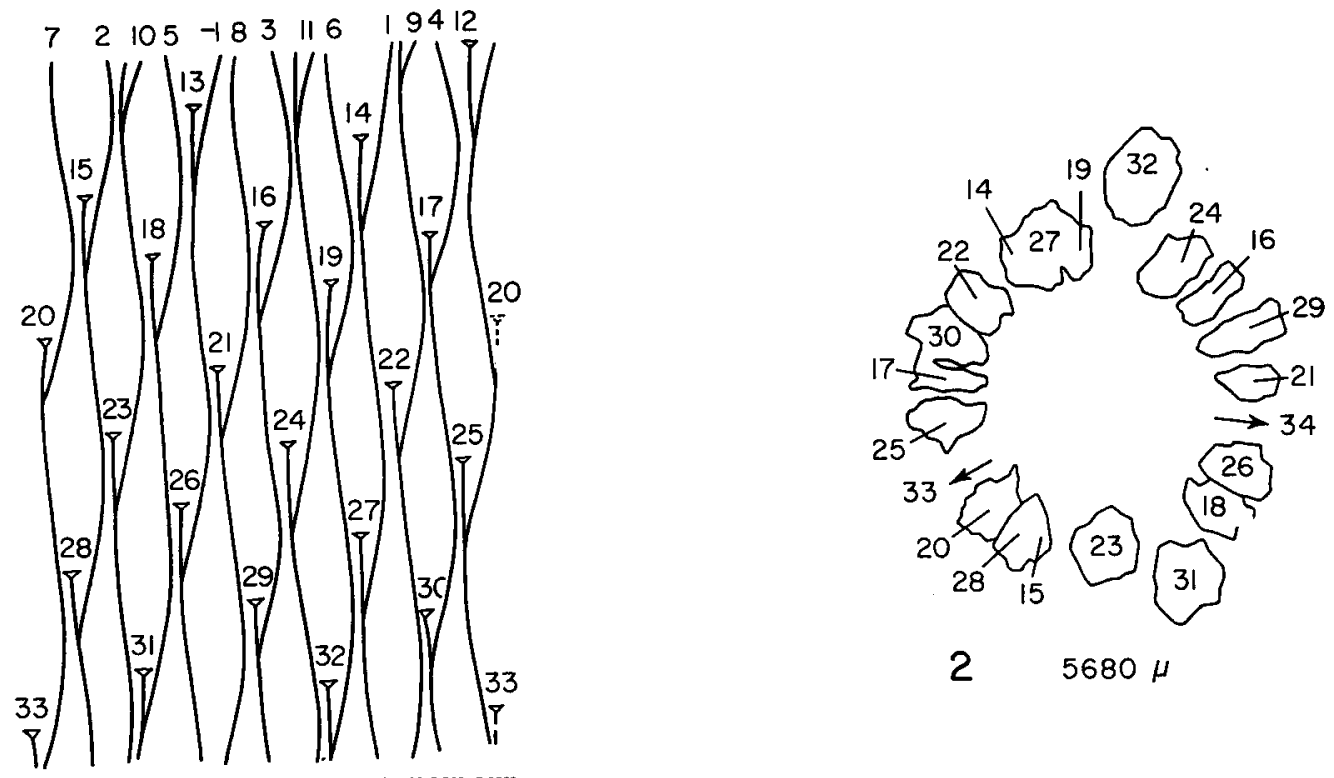

1
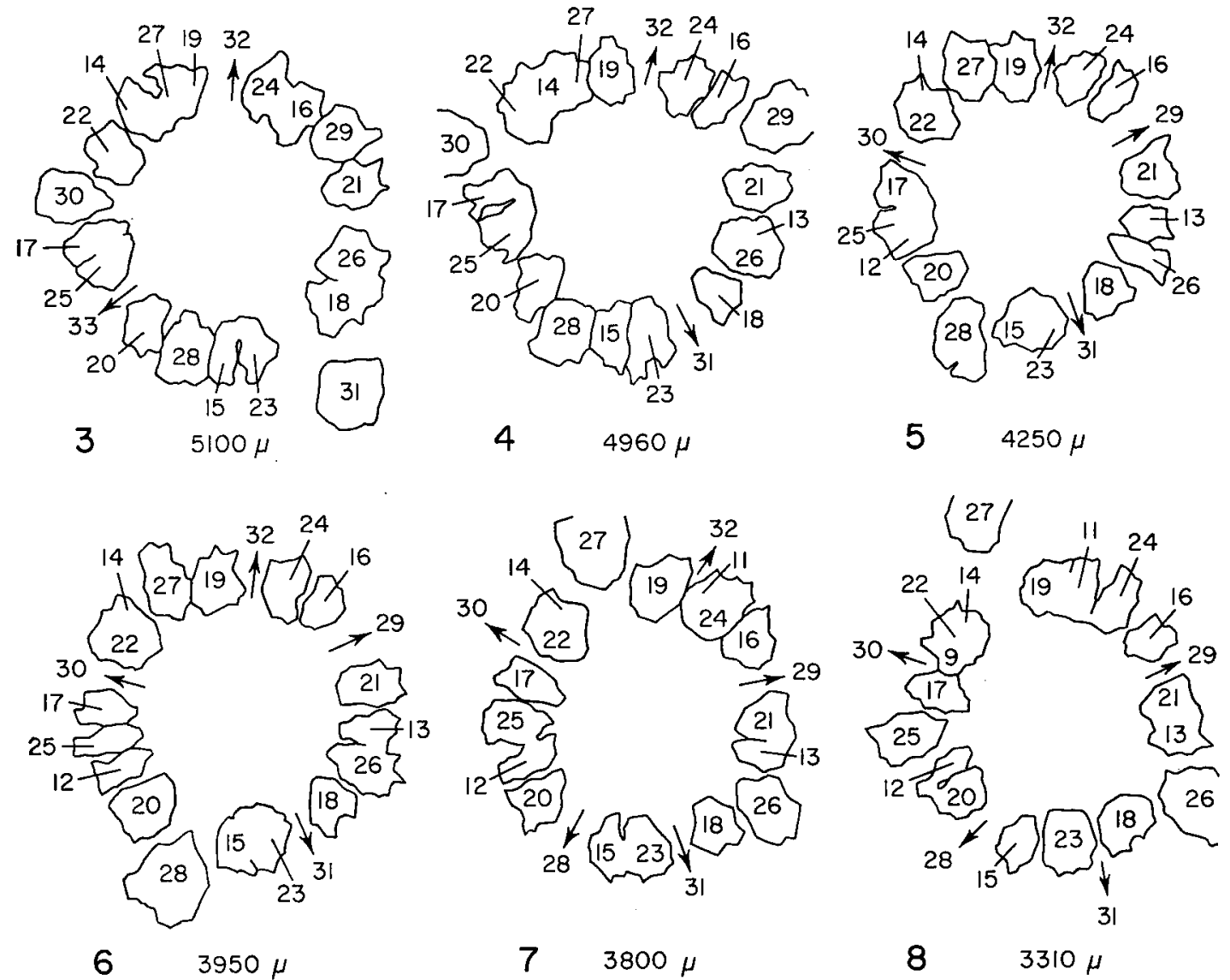


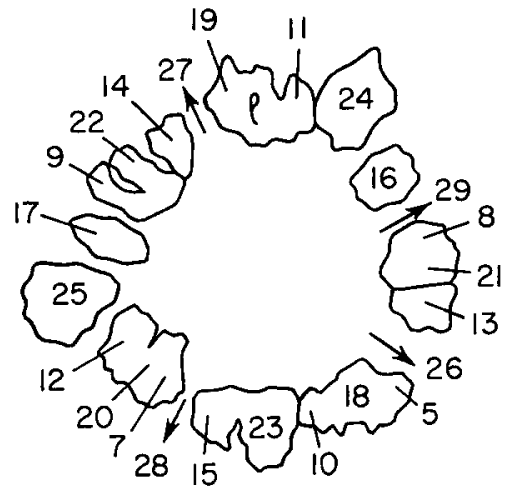

$92970 \mu$
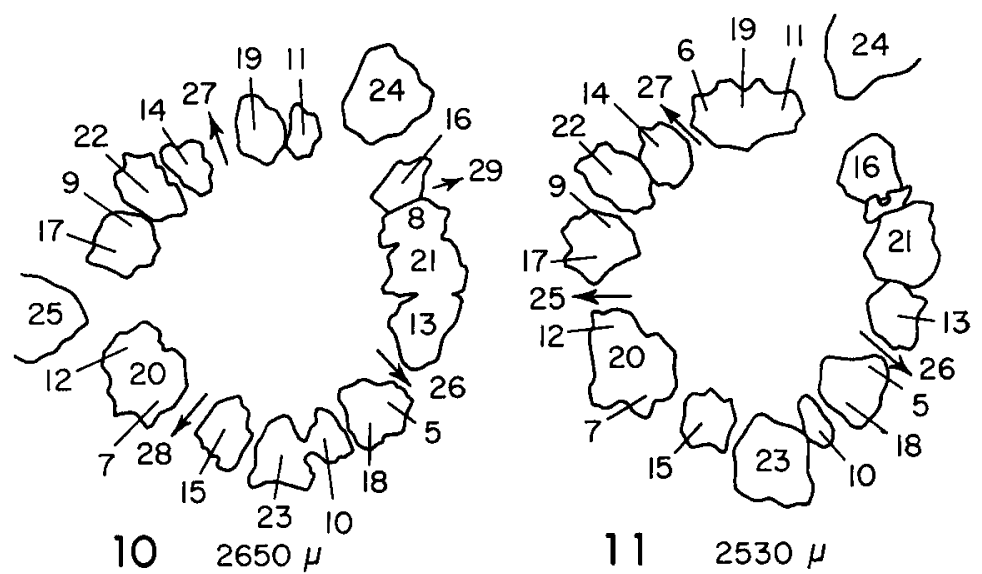

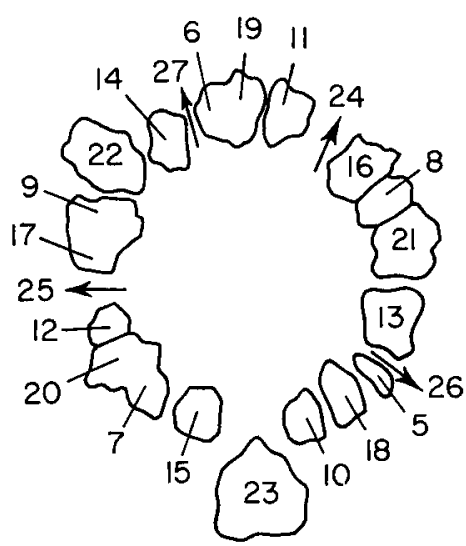

$122090 \mu$

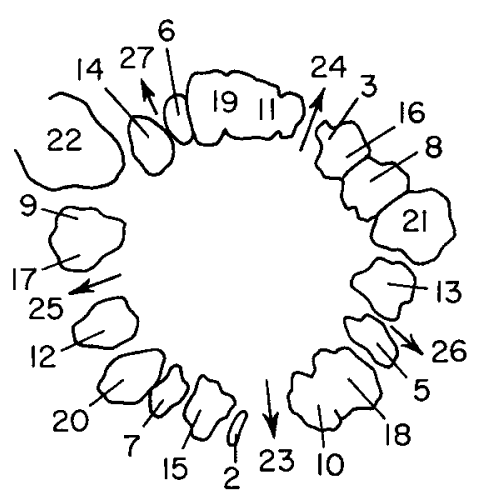

$131840 \mu$.

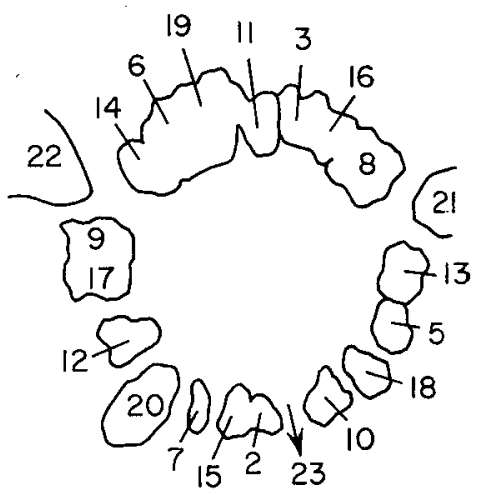

$14 \quad 1540 \mu$

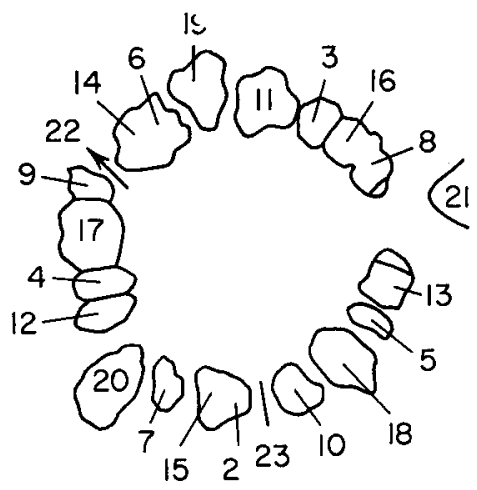

15

$1410 \mu$

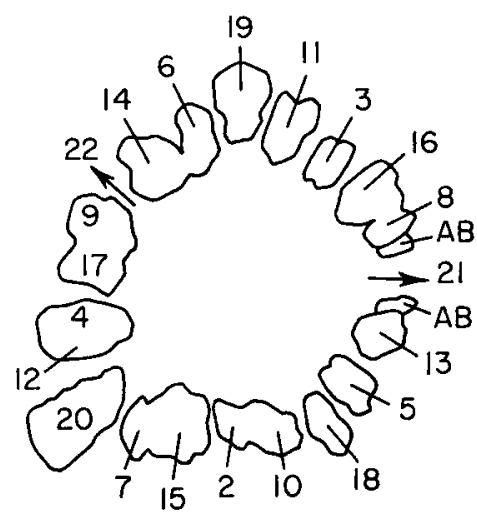

$16950 \mu$

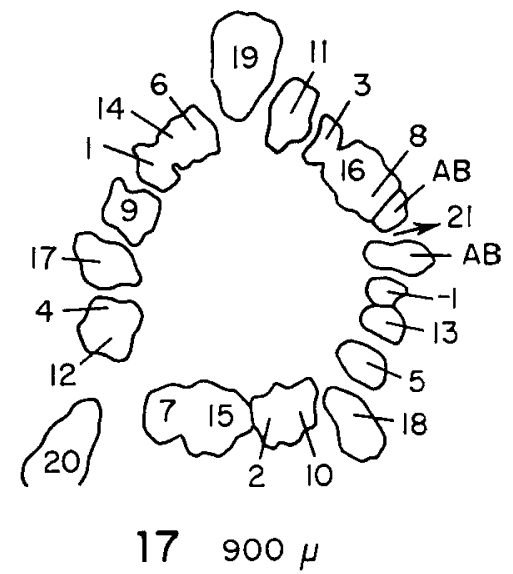

Fig. 9-17. Primary vascular structure of Abies concolor. Series of transverse sections at successive levels of an apex showing the details of the upward course of the vascular bundles. The sections are indicated by their distances below the summit of the apical dome. The leaf traces and the sympodial segments are designated by their ontogenetic sequential number as in Fig. 1. The features summarized in Fig. 1 can be traced in these diagrams. AB = axillary bud traces, $\times 70$. 


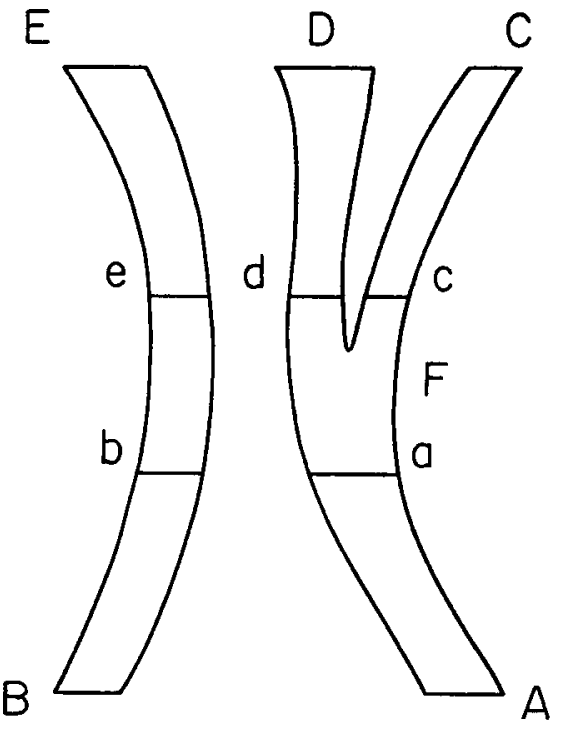

18

Fig. 18. Diagram illustrating the method of collection of data for statistical analysis of the tangential contacts.

a. Direction of the ontogenetic spiral--In all the specimens examined the ontogenetic spiral was found to follow either a sinistrorse or a dextrorse course. Different specimens of the same species and even different apices of the same plant (e.g., on the leader and the lateral shoots) have been found to show differences in the direction of the spiral. However, no specimen has been observed where there is a reversal of the ontogenetic spiral in the same shoot apex.

b. Angle of divergence-In all the species examined except Cedrus atlantica, the phyllotactic fractions follow those of the principal series with the average angle of divergence in each case approximating the limiting angle $\left(\begin{array}{lll}137^{\circ} 30^{\prime} & 6^{\prime \prime}\end{array}\right)$ associated with the principal series. (In bijugate forms due to the occurrence of two sibling spirals, the ideal angle is $68^{\circ} 45^{\prime}$, one-half of the ideal angle of the principal series.) In Cedrus atlantica a fraction of the secondary series with the angle of divergence $99^{\circ} 30^{\prime}$ has been observed. One similar instance has been reported by Barthelmess (1935) in Cedrus deodora, and two examples among 22 randomly selected apices of Sequoia sempervirens by Sterling (1945).

A bijugate condition, i.e, the presence of two parallel spirals, has been found in Torreya californica, Cephalotaxus drupacea, and Larix laricina in the present study. Bijugy has been reported in the first two genera by Geyler (1867), but to the writers' knowledge, it has not been reported previously in Larix.
TABLE 2. Coefficient of correlation between $x$ and $y$ and between $x$ and $z$, where $x=$ number of xylem cells in the leaf trace at the level $d$ in Fig. 18, $y=$ the difference in the number of xylem cells at the levels $a$ and $c$, and $z=$ the difference in the number of xylem cells at levels $b$ and $e$

\begin{tabular}{|c|c|c|c|}
\hline Species & $\begin{array}{c}\text { Number of } \\
\text { tangential } \\
\text { contacts }\end{array}$ & $r_{x y}$ & $\mathbf{r}_{\mathbf{x} x}$ \\
\hline Abies concolor & 15 & $0.667^{b}$ & -0.172 \\
\hline Abies holophylla & 10 & $0.744^{n}$ & 0.501 \\
\hline Cedrus atlantica & 15 & $0.678^{\mathrm{b}}$ & 0.418 \\
\hline Cedrus libani & 10 & $0.844^{b}$ & -0.148 \\
\hline Larix laricina & 10 & $0.865^{b}$ & 0.345 \\
\hline Picea abies & 10 & $0.876^{b}$ & -0.001 \\
\hline Picea pungens & 10 & $0.783^{a}$ & 0.264 \\
\hline Pinus strobus & 10 & $0.894^{b}$ & 0.341 \\
\hline Pseudotsuga taxifolia & 10 & $0.850^{\mathrm{b}}$ & 0.285 \\
\hline Cryptomeria japonica & 16 & $0.539^{\mathrm{a}}$ & 0.419 \\
\hline Cunninghamia & & & \\
\hline lanceolata & 10 & $0.797^{\mathrm{a}}$ & 0.429 \\
\hline $\begin{array}{l}\text { Sequoiadendron } \\
\text { giganteum }\end{array}$ & & & \\
\hline $\begin{array}{l}\text { giganteum } \\
\text { Taxodium distichum }\end{array}$ & 10 & $0.925^{b}$ & -0.264 \\
\hline $\begin{array}{l}\text { Taxodium distichum } \\
\text { Podocarpus }\end{array}$ & 10 & $0.824^{b}$ & 0.491 \\
\hline macrophyllus & 10 & $0.941^{\mathrm{b}}$ & 0.296 \\
\hline
\end{tabular}

a Significant at $5 \%$ level.

b Significant at $1 \%$ level.

c. Number of sympodia-Different genera examined in this study show the same number of sympodia, and specimens of the same species show different numbers. There are fewer sympodia in the seedling and lateral shoots than in mature and leader shoots (see also Geyler, 1867). The most common numbers of sympodia are 5, $8,13,21, \ldots$, the successive numbers of the Fibonacci series. In Cedrus atlantica 18 sympodia have been found, a number belonging to the secondary series. In Torreya californica and in Larix laricina with bijugate phyllotaxis there are 10 sympodia, and in Cephalotaxus drupacea, also exhibiting a bijugate condition, one branch shows 10 and another 16 sympodia. These sympodial numbers, 10 and 16, are double those of the numbers of the Fibonacci series, 5 and 8. Variation in the number of sympodia in the same shoot apex has been observed in four species in the present study. Of these, a decrease in number of sympodia was observed from 21 to 13 in Cedrus libani, 13 to 8 in Picea pungens, and from 8 to 5 in Taxus cuspidata. Similar decreases have been noted by Barthelmess (1935) in Cephalotaxus fortunei from 10 to 6 and Picea asperata from 8 to 3 , and by Camefort (1956) in Taxus baccata from 13 to 8. An increase in number of sympodia from 5 to 8 in Sequoiadendron giganteum is reported for the first time in this study.

d. Trace divergence-It has been mentioned 

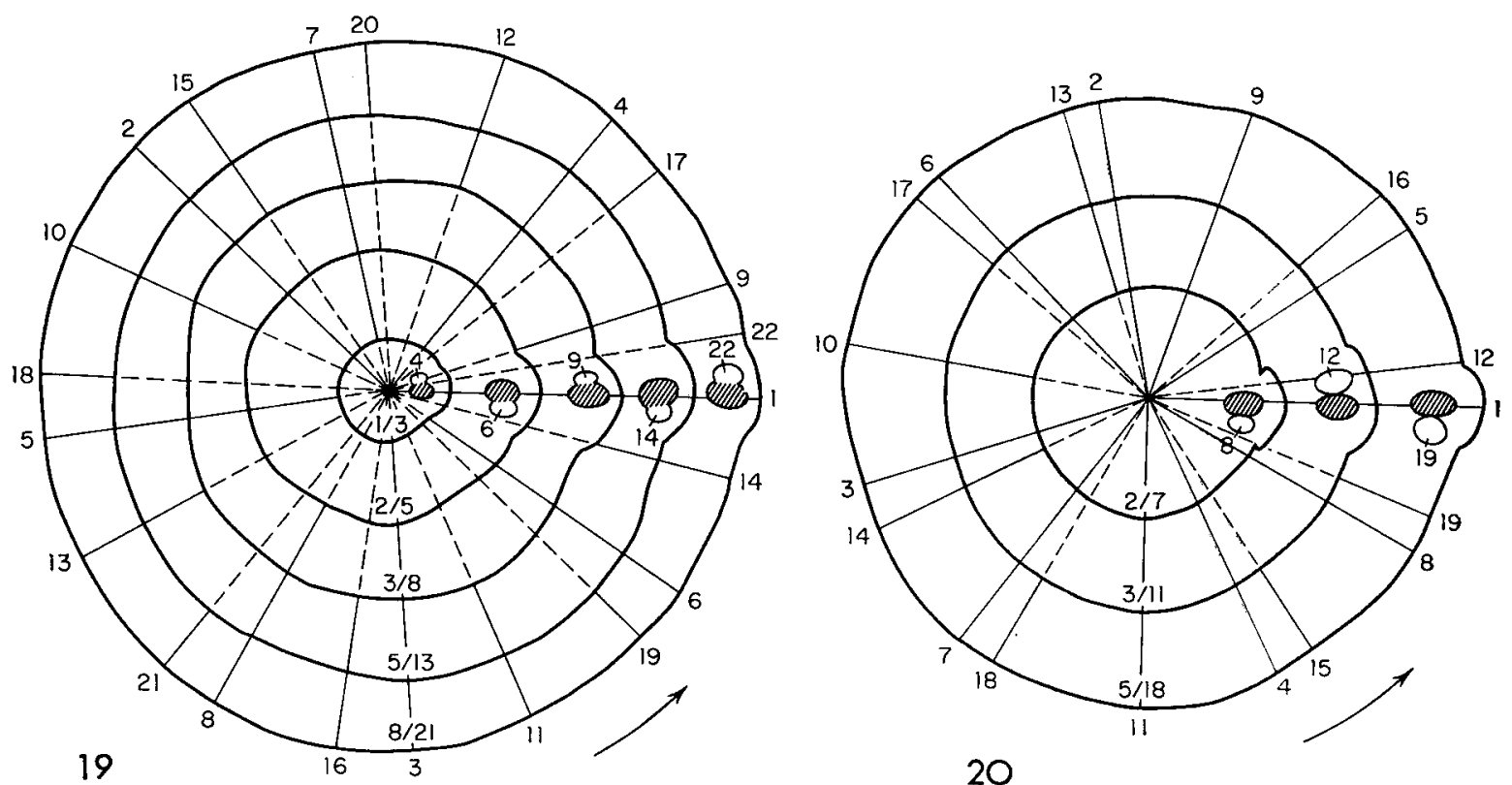

Fig. 19, 20.-Fig. 19. A diagram illustrating the relation between sympodial number and direction of trace divergence in conifers with phyllotactic fractions of the principal series. (Broken line indicates position of unformed future traces. Leaves are numbered in sequence, increasing values denoting decreasing age. Traces are shown cross-hatched. The arrow indicates the direction of the ontogenetic spiral.)-Fig. 20. A diagram illustrating the relation between the number of sympodia and the direction of trace divergence in conifers with spiral leaves with phyllotactic fractions of the secondary series. Broken lines represent positions of unformed future leaf traces. Leaves are numbered in sequence with increasing values denoting decreasing age. Traces are shown cross-hatched. The arrow indicates the direction of the ontogenetic spiral.

earlier that direction of trace divergence can be predicted accurately from a knowledge of the three characteristics just discussed. In order to illustrate this, Fig. 19, 20 have been prepared. Figure 19 is a schematic diagram in which the five concentric circles represent five superimposed transverse sections of apices of different diameter. All show the same limiting angle of divergence (ca. $137^{\circ} 30^{\prime}$ ) of the Fibonacci series between successive leaves numbered 1-22 in a dextrorse ontogenetic spiral with no. 1 representing the oldest leaf. The sympodial numbers in each case also follow the numbers of the Fibonacci series, i.e., $3,5,8,13,21, \ldots$ In each section the number of sympodia is assumed to be fixed; thus the innermost apex designated as $1 / 3$ (to show that one revolution of the ontogenetic spiral around the stem involves the insertion of three leaves) has 3 sympodia, $2 / 5$ has 5 , $3 / 8$ has $8,5 / 13$ has 13 , and $8 / 21,21$. Now it can be easily seen that because of the fixed number of sympodia, traces 1 and 4 have to arise from the same sympodium in the smallest apex. Because of the fixed angle of divergence, leaf 4 is inserted on the right side of leaf 1 , when viewed from the outside. Thus when sympodial segment 1 divides, it has to give rise to trace 1 on the left of the newly formed sympodial segment 4 , i.e., on the side away from the direction of the rising spiral. The trace divergence in this case, therefore, is sinistrorse. For the same reasons - constancy of sympodial number and limiting angle- the direction of trace divergence is found to be in the direction of the ontogenetic spiral in stems with 5 and 13 sympodia, and opposed to the direction of the ontogenetic spiral in stems with 8 and 21 sympodia, illustrated in the apices $2 / 5,5 / 13,3 / 8$, and $8 / 21$ respectively.

Figure 20 represents in a similar way sections of three superposed shoot apices, where the angle of divergence between successive leaves is fixed as $991 / 2^{\circ}$, the limiting angle of the secondary series. Hence the phyllotactic fractions

TABLE 3. Relationship between trace divergence and the direction of ontogenetic spiral, limiting angle of divergence, and number of sympodia

\begin{tabular}{|c|c|c|c|}
\hline $\begin{array}{l}\text { Direction } \\
\text { of the } \\
\text { ontogenetic } \\
\text { spiral }\end{array}$ & $\begin{array}{l}\text { Limiting } \\
\text { angle }\left(^{\circ}\right)\end{array}$ & $\begin{array}{l}\text { Number of } \\
\text { sympodia }\end{array}$ & $\begin{array}{c}\text { Direction of } \\
\text { trace } \\
\text { divergence }\end{array}$ \\
\hline Dextrorse & $1371 / 2$ & 3,8, and 2 & Sinistrorse \\
\hline Dextrorse & $1371 / 2$ & 5 and 13 & Dextrorse \\
\hline Sinistrorse & $1371 / 2$ & 3,8, and 21 & Dextrorse \\
\hline Sinistrorse & $1371 / 2$ & 5 and 13 & Sinistrorse \\
\hline Dextrorse & $99 \frac{1}{2}$ & 7 and 18 & Dextrorse \\
\hline Dextrorse & $991 / 2$ & 11 & Sinistrorse \\
\hline Sinistrorse & $991 / 2$ & 7 and 18 & Sinistrorse \\
\hline Sinistrorse & $991 / 2$ & 11 & Dextrorse \\
\hline
\end{tabular}


$2 / 7,3 / 11,5 / 18$ and sympodial numbers 7,11 , 18 also follow fractions and numbers of the secondary series. For each apex in the diagram the number of sympodia has been fixed; thus the apex with the phyllotactic fraction $2 / 7$ has $7,3 / 11$ has 11 , and $5 / 18$ has 18 sympodia. Because of the fixation of the angle of divergence and the number of sympodia, the trace divergence is seen to be in the same direction as the ontogenetic spiral, i.e., dextrorse in apices with 7 and 18 sympodia, and in the direction opposite to the ontogenetic spiral in an apex with 11 sympodia.

The relationship between the direction of trace divergence and the three factors, direction of the ontogenetic spiral, the limiting angle of divergence, and the number of sympodia, described above is summarized in Table 3 .

It can also be noted from Fig. 19 that when the number of sympodia in the vascular system remains constant, the number of sympodia intervening between any two sympodia from which leaf traces to successive leaves diverge along the ontogenetic spiral also remains constant. Thus between any two sympodia from which successive leaf traces diverge, say $\mathbf{n}$ and $\mathrm{n}-1$, there are no intervening sympodia when the total number of sympodia in the vascular system is 3 , and 1 when 5,2 when 8,4 when 13 , 7 when 21 .

This study, which has resulted in a characterization of the vascular system of some conifers with helical phyllotaxis, shows clearly that the vascular supply to a leaf in these forms orginates as a single bundle that branches from a sympodium. No evidence has been found to support the views of Jeffrey $(1899,1902,1917)$ that the eustele of the conifers has been derived from a siphonostele or that the conifer leaf gap is homologous with the fern leaf gap. The phylogenetic significance of these conclusions as well as a new interpretation of stelar evolution in gymnosperms will be presented in subsequent papers in this series.

\section{LITERATURE CITED}

Bailey, I. W. 1956. Nodal anatomy in retrospect. J. Arnold Arbor. 38: 269-287.

Barthelmess, A. 1935. Ưber den Zusammenhang zwischen Blattstellung und Stelenbau unterer besonderer Berücksichtigung der Koniferen. Bot. Arch. 37: 207-260.

BARY, A. DE. 1884. Comparative anatomy of the vegetative organs of the phanerogams and ferns. [English translation by F. O. Bower and D. H. Scott.] Oxford.

Benzing, D. H. 1967a. Developmental patterns in stem primary xylem of woody Ranales. I. Species with unilacunar nodes. Amer. J. Bot. 54: 805-813.

- $1967 \mathrm{~b}$. Developmental patterns in stem primary xylem of woody Ranales. II. Species with trilacunar and multilacunar nodes. Amer. J. Bot. 54: 813820.

Bertrand, C. E. 1874. Anatomie comparée des tiges et des feuilles chez les Genetacées et les Coniferes. Ann. Sci. Nat. Bot., Ser. V, 20:5-153.
Bisalputra, T. 1960. Anatomical and morphological studies in Chenopodiaceae I. Inflorescence of Atriplex and Bassia. Austral. J. Bot. 8: 226-242.

Camerort, H. 1956. Etude de la structure du point végetatif et des variations phyllotaxiques chez quelques gymnospermes. Ann. Sci. Nat., Ser. XI, 17: $1-185$.

Chindnler, A. 1950. Phyllotaxy. Amer. Mid. Natur. 44: $506-508$.

Crafts, A. S. 1943. Vascular differentiation in the shoot apex of Sequoia sempervirens. Amer. J. Bot. 30: 110-121.

EAmEs, A. J. 1931. The vascular anatomy of the flower with refutation of carpel polymorphism. Amer. J. Bot. 18: 147-188.

Esau, K. 1960. Anatomy of seed plants. John Wiley and Sons, New York.

——. 1965. Vascular differentiation in plants. Holt, Rinehart and Winston, New York.

Florin, R. 1931. Untersuchungen zur Stammesgeschichte der Coniferales und Cordaitales. Svenska Vetenskaps-Akad. Handl. Ser. 5, 10: 1-588.

Geyler, H. T. 1867. Ueber den Gefässbündelverlauf in. den Laubblattregionen der Coniferen. Jahrb. Wiss. Bot. 6: $55-208$.

Gunckel, J. E., AND R. H. Wetmore. 1946. Studies of development in long shoots and short shoots of Ginkgo biloba L. II. Phyllotaxis and organization of the primary vascular system: primary phloem and primary xylem. Amer. J. Bot. 33: 532-543.

Hilil, T. G., and E. DeFraine. 1913. A consideration of the facts relating to the structure of seedlings. Ann. Bot. 27: 257-272.

JefFREY, E. C. 1899. The morphology of the central cylinder in angiosperms. Trans. Can. Inst. 6: 599636 .

-_. 1902. The structure and development of the stem in the Pteridophyta and gymnosperms. Phil. Trans. Roy. Soc. London 195B: 119-146.

- 1917. The anatomy of woody plants. Univ. Chicago Press, Chicago.

Johansen, D. A. 1940. Plant microtechnique. McGraw-Hill, New York.

KumanI, G. K. 1963. The primary vascular system of gymnosperms: A comparative study based on thirty species of twenty-three genera of conifers augmented by data from extinct gymnosperms and progymnosperms. Ph.D. thesis, Univ. Michigan, Ann Arbor.

Marsden, M. P. F., and I. W. BaIley. 1955. fourth type of nodal anatomy in dicotyledons, : lustrated by Clerodendron trichotomum Thunb. J. Arnold Arbor. 36: 1-51.

- - and T. A. Steeves. 1955. On the primary vascular system and the nodal anatomy of Ephedra. J. Arnold Arbor. 36: 241-258.

Sinnotr, E. W. 1914. Investigations on the phylogeny of the angiosperms. I. The anatomy of the node as an aid in the classification of the angiosperms. Amer. J. Bot. 1: 303-322.

Sporne, K. R. 1948. A note on the rapid clearing technique of wide application. New Phytol. 47: 290-291.

Sterling, C. 1945. Growth and vascular development in the shoot apex of Sequoia sempervirens (Lamb.) Endl. II. Vascular development in relation to phyllotaxis. Amer. J. Bot. 32: 380-386.

- 1947. Organization of the shoot of Pseudotsuga taxifolia (Lamb.) Britt. II. Vascularization. Amer. J. Bot. 34: 272-280. 